\title{
INFLUÊNCIA DO NÍVEL DE ADUBAC̃̃̃O DE PLANTAS MATRIZES NA FORMAÇÃO DE MUDAS DE CAFEEIROS EM SISTEMA HIDROPÔNICO
}

\author{
Influence of the level of fertilization of the matrix plants in the formation of seedlings \\ of coffee plants in hydroponic systems
}

\author{
Bruno Galvêas Laviola ${ }^{1}$, Hermínia Emilia Prieto Martinez ${ }^{2}$, Aldo Luiz Mauri ${ }^{3}$
}

\begin{abstract}
RESUMO
Objetivou-se neste trabalho avaliar o desenvolvimento de mudas de quatro cultivares de cafeeiro arábico, originadas de sementes de plantas submetidas aos níveis de adubação baixo, adequado e alto, em sistema hidropônico com argila expandida. Utilizou-se, para este experimento, sementes de quatro cultivares de cafeeiro arábico (Catuaí, Rubi, Icatu e Acaiá), submetidos a três níveis de adubação. Os níveis baixo e alto de adubação receberam, respectivamente, 0,4 e 1,4 vezes a recomendação feita para o nível adequado. Após a coleta e preparo, as sementes foram germinadas em papel "germitest" e depois de 30 dias foram transplantadas para tubetes de $120 \mathrm{ml}$ preenchidos com substrato comercial. O sistema hidropônico empregado foi de subirrigação com argila expandida (cinasita) onde foram fixados os tubetes. Utilizou-se ainda o delineamento de blocos casualizados em esquema fatorial 4 X 3 com 4 repetições e 7 plantas úteis por parcela. Assim que as plantas atingiram 5 a 6 pares de folhas foi medida a altura de plantas, o peso de matéria seca das folhas, caule e sistema radicular. Os resultados obtidos foram submetidos à análise de variância e as médias comparadas pelo teste de Duncan. Observou-se que o nível de adubação das plantas matrizes pouco influenciou no crescimento e desenvolvimento das mudas de cafeeiro, no sistema hidropônico. O sistema hidropônico proposto promoveu bom desenvolvimento das respectivas mudas de cafeeiro.
\end{abstract}

Termos para indexação: Coffea arabica L.; Nutrição Mineral; Argila Expandida.

\begin{abstract}
The objective of this work was to evaluate the development of seedlings of four varieties of arabic coffee plant in hydroponic system with expanded clay. The seeds of the cultivars Catuaí, Rubi, Icatu e Acaiá were colected from plants submitted to three levels of fertilization. The low and high levels of fertilization received 0.4 and 1.4 times the recommendation done for the appropriate level, respectively. After the collection and preparation, the seeds were germinated in paper rolls and after 30 days they were transplanted to $120 \mathrm{ml}$ containers filled out with commercial substratum. The nutritive solution was supplied to the channels with expanded clay by sub-irrigation. The experimental design was in randomized blocks in a $4 \times 3$ factorial scheme with 4 replications and 7 useful plants per plot. As soon as the plants reached 5 to 6 pairs of leaves the height of plants and dry matter weight of leaves, stems and root system were measured. The obtained results were submitted to the variance analysis and the averages were compared by the Duncan test. It was observed that the level of fertilization of the matrix plants had little influence upon growth and development of the coffee plant seedlings. The proposed hydroponic system promoted adequate development of the coffee plant seedlings.
\end{abstract}

Index terms: Coffea arabica L; Mineral Nutrition; Expanded-Clay.

(Recebido em 23 de março de 2005 e aprovado em 22 de setembro de 2006)

\section{INTRODUÇÃO}

Um dos fatores de maior importância na formação de uma lavoura cafeeira é a produção de mudas sadias, com bom desenvolvimento. O sistema de produção de mudas adotado deve ser adequado de forma a não proporcionar somente um bom desenvolvimento das mudas no viveiro, como também, no campo (ALVARENGA et al., 2000; GUIMARÃES et al., 1998; MATIELLO et al., 2005).

Mudas de boa qualidade devem ter, primeiramente, um sistema radicular bastante desenvolvido, necessário para suprir as exigências nutricionais e de água. Além disso, a muda deve apresentar um caule com internódios não muito longos e uma área foliar sem perdas (MATIELLO et al., 2005). Uma maior área foliar, no início de desenvolvimento da muda, mantendo-se uma boa relação raiz/parte aérea, é importante para uma maior interceptação da energia luminosa e sua conversão em carboidratos, necessários ao crescimento da planta (LARCHER, 2004). No entanto, a formação de mudas de boa qualidade depende, primeiramente, da qualidade inicial das sementes (ALVARENGA et al., 2000).

\footnotetext{
'Engenheiro Agrônomo, Doutorando - Departamento de Fitotecnia/DFT - Universidade Federal de Viçosa/UFV - $36570-000$ - Viçosa, MG laviolabg@yahoo.com.br - Bolsista CNPq

²Engenheira Agrônoma, Doutora, Professora - Departamento de Fitotecnia/DFT - Universidade Federal de Viçosa/UFV - 36570-000 - Viçosa, MG herminia@ufv.br

${ }^{3}$ Engenheiro Agrônomo, Doutorando - Departamento de Fitotecnia/DFT - Universidade Federal de Viçosa/UFV - 36570-000 - Viçosa, MG aldmauri@yahoo.com.br
} 
A disponibilidade de nutrientes para as plantas influi na produção e na qualidade fisiológica da semente, por afetar a formação do embrião e dos órgãos de reserva, assim como a composição química e, conseqüentemente, o metabolismo e o vigor (CARVALHO \& NAKAGAWA, 2000). Sendo as reservas das sementes responsáveis pela nutrição das plântulas, no estágio inicial de crescimento (CARVALHO \& NAKAGAWA, 2000; MAGUIRE, 1962), uma maior quantidade de reservas acumuladas pode resultar em maior vigor e velocidade de crescimento inicial das plantas. Mauri et al. (2005) verificaram que uma melhor nutrição mineral das plantas matrizes poderá influenciar positivamente na germinação e vigor das sementes e, conseqüentemente, proporcionar mudas mais vigorosas e de melhor qualidade.

A utilização de sistemas hidropônicos, na produção de mudas, é amplamente empregado para fins de produção de mudas, que serão utilizadas nos próprios sistemas hidropônicos (MARTINEZ \& SILVA FILHO, 2004). No entanto, a produção de mudas hidropônicas para outros fins de cultivo é um processo novo e com grande potencialidade em seu uso. Como vantagens dos sistemas hidropônicos, na produção de mudas, podem citar menor tempo na produção das mudas, fornecimento mais adequado dos nutrientes minerais, melhor condições para o desenvolvimento da muda e melhor controle de doenças e pragas.

Assim, o objetivo deste trabalho foi avaliar o desenvolvimento de mudas de quatro cultivares de cafeeiro arábico, originadas de sementes de plantas submetidas a três níveis de adubação (baixo, adequado e alto), em sistema hidropônico, com argila expandida.

\section{MATERIAL E MÉTODOS}

O experimento foi realizado na casa de vegetação do Departamento de Fitotecnia da UFV, no período de 14 de setembro de 2003 a 12 de fevereiro de 2004 (aproximadamente 5 meses). Utilizaram para este experimento sementes de quatro cultivares de cafeeiro arábico (Catuaí, Rubi, Icatu e Acaiá), submetidos a três níveis de adubação. Os níveis baixo e alto de adubação receberam, respectivamente, 0,4 e 1,4 vezes a recomendação feita para o nível adequado. A adubação do nível adequado de adubação foi realizada com base em análise do solo e seguindo como referência o Manual de recomendações de Fertilizantes para o Estado de Minas Gerais (GUIMARÃES et al., 1999).

Após a coleta e preparo (ALVAREGA et al., 2000), as sementes foram germinadas em papel "germitest" e depois de 30 dias foram transplantadas para tubetes de $120 \mathrm{ml}$, preenchidos com substrato comercial.

O sistema hidropônico empregado foi de subirrigação com argila expandida (cinasita), onde foram fixados os tubetes. A solução nutritiva foi preparada com

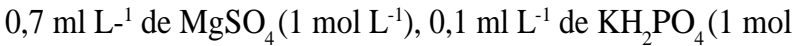
$\left.\mathrm{L}^{-1}\right), 1 \mathrm{ml} \mathrm{L}-1$ de $\mathrm{NH}_{4} \mathrm{NO}_{3}\left(1 \mathrm{~mol} \mathrm{~L}^{-1}\right), 1 \mathrm{ml} \mathrm{L}^{-1} \mathrm{de} \mathrm{Ca}\left(\mathrm{NO}_{3}\right)_{2}(1$ mol L-1 $), 2,3 \mathrm{ml} \mathrm{L}^{-1}$ de $\mathrm{KNO}_{3}\left(1 \mathrm{~mol} \mathrm{~L}^{-1}\right)$ e micronutrientes conforme Clarck (1975). Até o dia 05/12/2003, a solução nutritiva foi mantida com " $1 / 2$ força" ( $50 \%$ da concentração dos sais), e com um turno de rega/dia. Após este período a solução nutritiva foi elevada para "1 força" e aplicada com os seguintes turnos de regas: 06/12/2003 a 10/01/2004, 7 turnos de regas/dia; 11 a 26/01/2004, 3 turnos de regas/ dia; 27/01 a 03/02/2004, 1 turno de rega/dia e, 4 a 12/02/ 2004, 1 turno de rega a cada 3 dias. A área experimental foi composta de um calhetão medindo 3,75 x $0,85 \mathrm{~m}$.

Utilizou-se o delineamento de blocos casualizados em esquema fatorial 4 X 3, com 4 repetições, e 7 plantas úteis por parcela. Assim que as plantas atingiram 5 a 6 pares de folhas, mediu-se a altura de plantas, o peso de matéria seca das folhas, caule e sistema radicular. Os resultados obtidos foram submetidos à análise de variância e as médias comparadas pelo teste de Duncan.

\section{RESULTADOS E DISCUSSÃO}

A altura de plantas das cultivares Catuaí, Rubi e Icatu não foi influenciada pelos níveis de adubação (TABELA 1). Foi verificado que para estas cultivares, mesmo no nível baixo de adubação, o suprimento de nutrientes minerais foi suficiente para formação adequada das sementes. Tais resultados diferem dos encontrados na cultura da soja, na qual Guerra et al. (2003) e Mann et al. (2002) constataram que ocorreu uma melhoria na qualidade fisiológica de sementes de soja, quando se aumentava a dose de nutrientes oferecidos à planta matriz. No entanto, corroboram com Lima et al. (2000) os quais não observaram efeito da adubação na qualidade fisiológica de sementes de café. Já a cultivar Acaiá, apresentou menor altura de plantas no tratamento com nível baixo de adubação das plantas matrizes.

Entre as cultivares, observou-se que, independente do nível de adubação das plantas matrizes, a cultivar Acaiá apresentou maior altura de plantas. A cultivar Icatu, apesar de apresentar como característica porte alto (PEREIRA \& SAKIYAMA, 1999), não apresentou diferença estatística na altura, no estádio inicial de desenvolvimento comparado às cultivares Catuaí e Rubi. Os resultados de altura de plantas das cultivares estão superiores aos resultados médios encontrado por Mendonça et al. (2002), e Santos 
et al. (2001) e próximos aos observados por Campos et al. (2001), em sistemas convencionais de produção de mudas em tubetes. Apesar das condições experimentais diferirem, pode-se verificar, por tais comparações, que o sistema hidropônico proposto promoveu crescimento adequado da parte aérea das mudas de cafeeiro.

Apenas a cultivar Rubi apresentou maior peso de matéria seca das folhas, no nível alto de adubação das plantas matrizes, porém, as médias foram estatisticamente iguais às observadas no nível baixo de adubação (TABELA 2). As demais cultivares não sofreram influência do nível de adubação das plantas matrizes, no crescimento foliar. Entre as cultivares, verificou-se que estas apresentaram resultados estatisticamente iguais, independentes do nível de adubação ao qual as plantas matrizes foram submetidas. Observa-se que as cultivares consideradas de porte alto (Icatu e Acaiá), podem ter maior altura de mudas, mas isto não implica em maior crescimento foliar.

Mendonça et al. (2002), trabalhando com produção de mudas da cultivar Rubi em tubetes, encontrou resultado médio de peso de matéria seca de folhas de 0,52 g. Tais resultados são inferiores ao menor valor observado de peso de matéria seca de folhas neste experimento. Pode-se inferir que, neste trabalho, as mudas apresentaram crescimento foliar adequado no sistema hidropônico, independente do nível de adubação das plantas matrizes
(TABELA 2). Um maior crescimento foliar em mudas é desejável, já que as folhas realizam processos de conversão de energia luminosa em energia química (MARENCO \& LOPES, 2005; TAIZ \& ZEIGER, 2004), essencial para seu crescimento e desenvolvimento.

Na TABELA 3 observa-se que o nível de adubação das plantas matrizes influenciou apenas no acúmulo de matéria seca do caule da cultivar Acaiá. Entre as cultivares, no nível baixo de adubação, não se observou diferença estatística. Já nos níveis adequado e alto, a cultivar Acaiá apresentou, nos tratamentos maiores, acúmulo de matéria seca no caule. O maior acúmulo de matéria seca do caule na cultivar Acaiá era esperado, já que esta cultivar apresentou maior altura de plantas (TABELA 1).

Os resultados de matéria seca do sistema radicular de mudas de quatro cultivares de cafeeiro arábico, produzidas em sistema hidropônico de acordo com o nível de adubação das plantas matrizes, podem ser verificados na TABELA 4. O sistema radicular das cultivares Catuaí e Acaiá não foi influenciado, estatisticamente, pelo nível de adubação. Observou-se entre as cultivares que o peso de matéria seca das raízes apresentou comportamento diferenciado nos níveis baixo e adequado de adubação. No nível alto de adubação, as cultivares não apresentaram diferença estatística no peso de matéria seca e raízes. Comparando-se aos resultados encontrados por Gualberto et al. (2000) e Santos et al. (2001),

TABELA 1 - Altura $(\mathrm{cm})$ de mudas de quatro cultivares de cafeeiro arábico, de acordo com o nível de adubação das plantas matrizes, produzidas em sistema hidropônico.

\begin{tabular}{ccccc}
\hline \multirow{2}{*}{ Nível de Adubação } & \multicolumn{3}{c}{ Cultivares } & Acaiá \\
\cline { 2 - 5 } & Catuaí & Rubi & $14,40 \mathrm{a}$ & $15,36 \mathrm{a}$ B \\
Baixo & $12,83 \mathrm{~b}$ & $12,86 \mathrm{~b}$ & $14,02 \mathrm{~b}$ & $17,49 \mathrm{a} \mathrm{A}$ \\
Adequado & $14,13 \mathrm{~b}$ & $12,03 \mathrm{c}$ & $13,36 \mathrm{~b}$ & $17,93 \mathrm{a} \mathrm{A}$ \\
Alto & $13,74 \mathrm{~b}$ & $13,52 \mathrm{~b}$ &
\end{tabular}

*As médias na coluna e na linha seguidas da mesma letra maiúscula e minúscula, respectivamente, não diferem estatisticamente entre si ao nível de $5 \%$ de probabilidade, pelo teste Duncan.

TABELA 2 - Matéria seca (g) das folhas de mudas de quatro cultivares de cafeeiro arábico de acordo com o nível de adubação das plantas matrizes, produzidas em sistema hidropônico.

\begin{tabular}{ccccc}
\hline \multirow{2}{*}{ Nível de Adubação } & \multicolumn{3}{c}{ Cultivares } \\
\cline { 2 - 5 } & Catuaí & Rubi & Icatu & Acaiá \\
\hline Baixo & 1,27 & $1,08 \mathrm{AB}$ & 1,25 & 1,01 \\
Adequado & 1,15 & $0,95 \mathrm{~B}$ & 0,99 & 0,98 \\
Alto & 1,33 & $1,28 \mathrm{~A}$ & 1,14 & 1,24 \\
\hline
\end{tabular}

*As médias na coluna e na linha, seguidas da mesma letra maiúscula e minúscula, respectivamente, não diferem, estatisticamente, entre si ao nível de 5\% de probabilidade, pelo teste Duncan. 
TABELA 3 - Matéria seca (g) do caule de mudas de quatro cultivares de cafeeiro arábico, de acordo com o nível de adubação das plantas matrizes, produzidas em sistema hidropônico.

\begin{tabular}{ccccc}
\hline \multirow{2}{*}{ Nível de Adubação } & \multicolumn{5}{c}{ Cultivares } \\
\cline { 2 - 5 } & Catuaí & Rubi & Icatu & Acaiá \\
\hline Baixo & 0,2 & 0,19 & 0,24 & $0,22 \mathrm{~B}$ \\
Adequado & $0,20 \mathrm{ab}$ & $0,15 \mathrm{~b}$ & $0,20 \mathrm{ab}$ & $0,24 \mathrm{a} \mathrm{AB}$ \\
Alto & $0,25 \mathrm{ab}$ & $0,21 \mathrm{~b}$ & $0,21 \mathrm{~b}$ & $0,29 \mathrm{a} \mathrm{A}$ \\
\hline
\end{tabular}

* As médias na coluna e na linha seguidas da mesma letra maiúscula e minúscula, respectivamente, não diferem, estatisticamente, entre si ao nível de 5\% de probabilidade, pelo teste Duncan.

TABELA 4 - Matéria seca (g) da raíz de mudas de quatro cultivares de cafeeiro arábico, de acordo com o nível de adubação das plantas matrizes, produzidas em sistema hidropônico.

\begin{tabular}{ccccc}
\hline \multirow{2}{*}{ Nível de Adubação } & \multicolumn{4}{c}{ Cultivares } \\
\cline { 2 - 5 } & Catuaí & Rubi & Icatu & Acaiá \\
\hline Baixo & $0,26 \mathrm{ab}$ & $0,25 \mathrm{~b} \mathrm{AB}$ & $0,30 \mathrm{a} \mathrm{A}$ & $0,22 \mathrm{~b}$ \\
Adequado & $0,21 \mathrm{ab}$ & $0,21 \mathrm{~b} \mathrm{~B}$ & $0,24 \mathrm{ab} \mathrm{B}$ & $0,27 \mathrm{a}$ \\
Alto & $0,28 \mathrm{a}$ & $0,28 \mathrm{a} \mathrm{A}$ & $0,27 \mathrm{a} \mathrm{AB}$ & $0,26 \mathrm{a}$ \\
\hline
\end{tabular}

* As médias na coluna e na linha seguidas da mesma letra maiúscula e minúscula, respectivamente, não diferem estatisticamente entre si ao nível de $5 \%$ de probabilidade, pelo teste Duncan.

em sistema convencional de produção de mudas em tubetes, observa-se que o peso da matéria seca do sistema radicular, neste experimento, está abaixo do encontrado por estes autores. No entanto, quando se compara ao trabalho realizado por Mendonça et al. (2002) observa-se que o valor médio de matéria seca do sistema radicular, encontrado por estes autores, está próximo a inferior aos valores observados por este trabalho. A formação de um sistema radicular bem desenvolvido em mudas é fundamental para se ter sucesso na constituição de um cafezal. De acordo com Rena \& DaMatta (2002), o sistema radicular desempenha funções importantíssimas nas plantas como elementos de suporte na matriz física do solo. Eles são órgãos de absorção de água e minerais, atuam na produção de várias substancias orgânicas essências a fisiologia da planta e são órgão de armazenamento de diversos nutrientes.

\section{CONCLUSÕES}

De modo geral, os níveis de adubação das plantas matrizes influenciaram no crescimento e desenvolvimento das mudas de cafeeiros arábicos.

As cultivares, bem como, as características avaliadas apresentaram respostas diferenciadas aos níveis de adubação das plantas matrizes.

\section{REFERÊNCIAS BIBLIOGRÁFICAS}

ALVARENGA, A. P.; MOURA, V. M.; RIBEIRO, M. F. Escolha de cultivares e produção de mudas de café. Viçosa: UFV, 2000. 21 p. (Boletim de extensão, 42).

CAMPOS, K. P. de; SANTOS, E. C.; CORRÊA, J. D.; SOUZA, C. A. S. de; SANTOS JÚNIOR, A. M. dos. Desenvolvimento de mudas de cafeeiro Acaiá, Topázio e Catuaí em diferentes espaçamentos e tamanhos de tubetes. In: CONGRESSO BRASILEIRO DE PESQUISASCAFEEIRAS, 27., 2001, Uberaba, MG. Anais... Rio de Janeiro: PROCAFÉ, 2001. p. 232-234.

CARVALHO, N. M.; NAKAGAWA, J. (Eds.). Sementes: ciência, tecnologia e produção. 4. ed. Jaboticabal: Funep, 2000. 588 p.

CLARK, R. B. Characterization of phosphate of intact morize roots. Journal Agricultural Food Chemistry, Madison, v. 23, p. 458-460, 1975.

GUALBERTO, R.; OLIVEIRA, P. S. R.; FAVORETO, A. J.; MOTTA FILHO, C. Avaliação de substratos comerciais na produção de mudas de cafeeiro (Coffea arabica L.) em tubetes. In: CONGRESSO BRASILEIRO DE PESQUISAS, 26., 2000, Marília, SP.Anais... Rio de Janeiro: PROCAFÉ, 2000. p. 327-328. 
GUERRA, C. A.; ROBAINA, A. D.; MARCHETTI, M. E.; SOUZA, L. C. F.; GONÇALVES, M. C.; NOVELINO, J. O. Qualidade fisiológica de sementes de soja em função do fósforo, molibdênio e cobalto. In: CONGRESSO BRASILEIRO DE CIÊNCIA DO SOLO, 29., 2003, Ribeirão Preto, SP. Anais... Ribeirão Preto: USP, 2003. CD-ROM.

GUIMARÃES, P. T. G.; ALVES NETO, A. de; BELINI JÚNIOR, O.; ADÃO, W. A.; SILVA, E. M. da. A produção de cafeeiros em tubetes. Informe Agropecuário, Belo Horizonte, v. 19, n. 193, p. 98-109, 1998.

GUIMARÃES, P. T. G.; GARCIA, A. W. R.; ALVAREZ, V. H.; PREZOTTI, L. C.; VIANA, A. S.; MIGUEL, A. E.; MALAVOLTA, E.; CORRÊA, J. B.; LOPES, A. S.; NOGUEIRA, F. D.; MONTEIRO, A. V. C. Cafeeiro. In: RIBEIRO, A. C.; GUIMARÃES, P. T. G.; ALVAREZ, V. H. (Eds.). Recomendações para o uso de corretivos e fertilizantes em Minas Gerais: $5^{a}$ aproximação. Viçosa: CFSEMG, 1999. p. 289-302.

LARCHER, W. Ecofisiologia vegetal. São Carlos: RiMa, 2004. $531 \mathrm{p}$.

LIMA, D. M.; CUNHA, R. L da; PINHO, E. V. R. von; GUIMARÃES, R. J. Efeito de adubações foliares em pré e pós florada na produção e qualidade das sementes de cafeeiro. In: SIMPÓSIO DE PESQUISA DOS CAFÉS DO BRASIL, 2001, Brasília, DF. Resumos... Brasília, DF: Embrapa Café; Belo Horizonte: Minasplan, 2001. p. 1448-1450.

MAGUIRE, J. D. Speed of germination aid seedling emergence and vigor. Crop Science, Madison, v. 2, p. 176-177, 1962.

MANN, E. N.; RESENDE, P. M. de; MANN, R. S.; CARVALHO, J. G. de; PINHO, E. V. R. von. Efeito da aplicação de manganês no rendimento e na qualidade fisiológica de sementes de soja. Pesquisa Agropecuária Brasileira, Brasília, v. 37, n. 12, p. 1757-1764, 2002.

MARENCO, R. A.; LOPES, N. F. Fisiologia vegetal: fotossíntese, respiração, relações hídricas e nutrição mineral. Viçosa: UFV, 2005. 451 p.
MARTINEZ, H. E. P.; SILVA FILHO, J. B. da. Introdução ao cultivo hidropônico de plantas. 2. ed. Viçosa: UFV, 2004. $111 \mathrm{p}$.

MATIELLO, J. B. et al. Cultura de café no Brasil: novo manual de recomendações. Rio de Janeiro: MAPA/ PROCAFE, 2005. 438 p

MAURI, A. L.; LAVIOLA, B. G.; ARAÚJO, E. F.; MARTINEZ, H. E. P.; NEVES, Y. P. Influência da adubação na qualidade fisiológica de sementes de quatro cultivares de café (Coffea arabica L.). Revista Ceres, Viçosa, v. 52, n. 301, p. 335-341, 2005.

MENDONÇA, F. C.; TEODORO, R. E. F.; LIMA, L. M. L. de; FERNANDES, D. L.; ALMEIDA, F. G. de; CUNHA, Á. A. da. Produção de mudas de café (Coffea arabica L.) cv. Rubi em tubetes com polímero hidroabsorvente adicionado ao substrato. In: SIMPÓSIO BRASILEIRO DE PESQUISA EM CAFEICULTURA IRRIGADA, 2002, Uberlândia.

Anais... Uberlândia: UFU, 2002. p. 177-180.

PEREIRA, A. P.; SAKIYAMA, N. S. Cultivares melhoradas de café arábica. In: ENCONTRO DEPRODUÇÃO DE CAFÉ COM QUALIDADE, 1999, Viçosa, MG. Anais... Viçosa: UFV, 1999. p. 241-257.

RENA, A.; DaMATTA, F. M. O sistema, a radicular do cafeeiro: morfologia e ecofisiologia. In: ZAMBOLIM, L. O estado da arte de tecnologias na produção de café. Viçosa: UFV, 2002. p. 11-92.

SANTOS, E. C.; CAMPOS, K. P.; SOUZA, S. L.; CORRÊA, J. B. D.; GUIMARÃES, R. J. Desenvolvimento de mudas de cafeeiro (Coffea arabica L.) produzidas em diferentes substratos, fertilizações e tamanhos de tubetes. In: SIMPÓSIO DE PESQUISA DOS CAFÉS DO BRASIL, 2001, Brasília, DF. Resumos... Brasília, DF: Embrapa Café, 2001. p. 1707-1713.

TAIZ, L.; ZEIGER, E. Fisiologia vegetal. 3. ed. Porto Alegre: Artmed, 2004. 719 p. 